\title{
Nursing diagnoses in a psychiatric emergency service: contribution to care systematization
}

\author{
Diagnósticos de enfermagem num serviço de urgência psiquiátrica: contributos para a \\ sistematização dos cuidados \\ Diagnósticos de enfermería en un servicio de urgencias psiquiátricas: contribuciones a la \\ sistematización de los cuidados
}

Ricardo Jorge de Sousa Antunes*; Francisca Gertrudes Caeiro Roberto Manso**

\begin{abstract}
Background: In a psychiatric emergency service, there is a diversity of clinical situations that reflect different nursing needs and problems.

Objective: To identify the most common mental health-related nursing diagnoses in a psychiatric emergency service.

Methodology: Extensive-quantitative study in a sample of 49 patients in the psychiatric emergency service. Elaboration of nursing diagnoses according to the International Classification for Nursing Practice (ICNP) and using the Mini-Mental State Examination, the Measure of Adherence to Treatment (MAT), and the Markova and Berrios Insight Scale.

Results: Impaired therapeutic adherence was the most common diagnosis, followed by a high prevalence of diagnoses related to psychotic symptoms and the psychological domain of mood, such as sadness, anxiety, and negative self-esteem.
\end{abstract}

Conclusion: The changes in the domain of psychotic symptoms represent the main nursing diagnoses and challenges.

Keywords: psychiatric nursing; nursing diagnosis; mental disorders; emergency services, psychiatric

\section{Resumo}

Enquadramento: Num serviço de urgência psiquiátrica acorrem uma diversidade de situaçôes clínicas que traduzem diferentes necessidades e problemas de enfermagem. Objetivo: Identificar os diagnósticos de enfermagem, no domínio da doença mental, mais frequentes num serviço de urgência psiquiátrica.

Metodologia: Investigação extensiva-quantitativa numa amostra de 49 clientes que acorreram ao serviço de urgência psiquiátrica. Elaboração dos diagnósticos de enfermagem segundo a Classificação Internacional para a Prática de Enfermagem (CIPE), com a mobilização dos instrumentos de aferiçáo: Mini-Exame do Estado Mental; Medida da Adesão Terapêutica (MAT) e Escala de Insight de Markova Berrios.

Resultados: A adesão ao regime terapêutico comprometido constituiu o diagnóstico de enfermagem mais frequente, destacando-se, também, uma grande prevalência de diagnósticos relacionados com a sintomatologia psicótica e com o domínio psicológico do humor, como a tristeza, a ansiedade e a baixa autoestima.

Conclusáo: As alteraçóes verificadas no domínio da sintomatologia psicótica representam a maior concentração de diagnósticos e de desafios de enfermagem.

Palavras-chave: enfermagem psiquiátrica; diagnóstico de enfermagem; transtornos mentais; serviços de urgência psiquiátrica

*Ph.D., Specialist Nurse, Lisbon School of Nursing, 1600-190, Lisboa, Portugal [riantunes2003@sapo.pt].Contribution to the article: literature search, theoretical background elaboration, questionnaire design, data collection and application of questionnaires, statistielaboration, questionnaire design, data collection and app
cal treatment, data analysis and discussion, article writing.

cal treatment, data analysis and discussion, article writing.
Address for correspondence: Rua de São Silvestre n¹8, 1600-190, Lisboa, Portugal.

**Ph.D., Coordinating Professor, Lisbon School of Nursing. 1600-190, Lisboa, Portugal [francisca.roberto@esel.pt]. Contribution to the article: literature search, theoretical background elaboration, questionnaire design, data analysis, article writing and revision.

\section{Resumen}

Marco contextual: A un servicio de urgencias psiquiátricas acuden una diversidad de cuadros clínicos que traducen diferentes necesidades y problemas de enfermería.

Objetivo: Identificar los diagnósticos de enfermería en el dominio de la enfermedad mental más frecuentes en un servicio de urgencia psiquiátrica.

Metodología: Investigación extensiva y cuantitativa en una muestra de 49 pacientes que acuden al servicio de urgencias psiquiátricas. Elaboración de los diagnósticos de enfermería según la Clasificación Internacional para la Práctica de Enfermería (CIPE), con el uso de los siguientes instrumentos de evaluación: Miniexamen del Estado Mental; Medida da Adhesión Terapéutica (MAT) y Escala de Insight de Markova Berrios.

Resultados: La adhesión al régimen terapéutico comprometido constituyó el diagnóstico de enfermería más frecuente, aunque destacó también una gran prevalencia de diagnósticos relacionados con la sintomatología psicótica y con el dominio psicológico del humor, como la tristeza, la ansiedad y la baja autoestima.

Conclusión: Los cambios observados en el ámbito de la sintomatología psicótica representan la mayor concentración de diagnósticos y de desafíos por parte de los enfermeros.

Palabras clave: enfermería psiquiátrica; diagnóstico de enfermería; transtornos mentales; servicios de urgencia psiquiátrica

Received for publication: 18.05.17

Accepted for publication: 13.07 .17 


\section{Introduction}

In a psychiatric emergency service, nursing interventions are mostly directed at the acute phases of the disease or the first episodes of disease onset. In Portugal, the psychiatric emergency service is a point of entry to the National Health Service and a useful resource for consultations and medical and nursing care. However, and despite the centrality of this type of service, the nursing theoretical production and empirical research on this topic is very scarce in Portugal. With regard to knowledge production, a psychiatric emergency service is an important unit of empirical analysis due to the variety of situations in this service and the fact that patients and family members provide information and present conditions that reflect very recent events. This allows a greater awareness about the emotional and thinking processes that lead people to seek professional help. Although these professional settings require a timely intervention and clinical reasoning, it is still necessary to use a common terminology based on a standardized nursing scientific discourse. According to Passos, Sequeira, and Fernandes (2014), the standardization of nursing documentation is essential since it enhances clinical practice and systematizes care through the identification of nursing-sensitive diagnoses, interventions, and outcomes.

In order to address some of these challenges, this study focuses on the importance of nursing diagnoses, even in psychiatric emergency settings. The research follows a theoretical-empirical orientation based on nursing diagnosis as a dynamic, organized, and complex stage of the nursing process in which decision making involves not only human responses but also critical assessments. The orientation that underlies the formulation of nursing diagnoses is based on the International Classification for Nursing Practice (ICNP; Conselho Internacional de Enfermeiros, 2016). It should be noted that this study is in line with other nursing studies that emphasize the prevalence of nursing diagnoses that emerge from nurses' daily work, such as those of Amaral (2010), Carvalho (2010), Passos et al. (2014), and Sequeira (2006). The main objective of this study is to identify the most common mental health-related nursing diagnoses among patients in psychiatric emergency settings. A more detailed analysis will explore the association be- tween nursing diagnoses and sociodemographic dimensions, medical diagnoses, cognitive status, degree of adherence to the therapeutic regimen, and degree of insight.

\section{Background}

In Portugal, psychiatric disorders currently affect more than a fifth of the Portuguese population (Observatório Português dos Sistemas de Saúde, 2015). With regard to the production of knowledge about mental illness, a psychiatric emergency service is a privileged place for nursing research. Nursing interventions in a psychiatric emergency service require rapid clinical reasoning and care delivery; however, the need for rapid responses does not mean that the interventions are mechanical actions automatically performed without reflection-on-action. In fact, unlike the more spontaneous social representation, most nursing interventions in psychiatric emergency services are based on Nurse-patient/family relationship, as shown by Antunes (2016) and Buriola, Kantorski, Sales, and Matsuda (2016). In a psychiatric emergency service, there is a diversity of clinical situations that reflect different nursing needs and problems. It is precisely due to this heterogeneity of complex situations that it is important to argue for the need to use a common terminology based on the definition of nursing diagnoses.

The formulation of nursing diagnoses results from a conceptual mental process of multidimensional evaluation and assessment of the status of a patient's focus of attention. According to Sequeira (2006), nursing diagnoses should have a multidimensional conceptual basis rooted in the following domains: clinical practice, clinical judgment, and risk/probability. It is assumed that diagnoses are not determined in advance; instead, they result from a process of dialectical construction encompassed in the relationship with the patient and are based on a combination of concepts derived from the axes defined by the ICNP. Therefore, Amaral (2010) argues nursing diagnoses and medical diagnoses should not be automatically associated. However, an analysis that includes the reality of daily nursing practice should consider that the various clinical decisions and choices of interventions have multiple levels of implications and influences 
that, together, can interfere with the elaboration of the most theoretical components of nursing practice. In psychiatric emergency settings, the specificities inherent to caring may hinder the formulation of diagnoses based on the selection and combination of individual concepts in ICNP axes. Therefore, and in order to support the use of nursing diagnoses in clinical settings, the ICNP catalogs (Conselho Internacional de Enfermeiros, 2016) are pre-coordinated sets of statements for a particular area of care or a specialty, which can be used to quickly and accurately document diagnoses.

\section{Research questions}

What are the most common psychiatric nursing diagnoses among patients in psychiatric emergency services?

What is the relationship between these nursing diagnoses and patients' systems of social relations, medical condition, cognitive function, degree of therapeutic adherence, and degree of insight?

\section{Methodology}

The methodological design has a descriptive and correlational component and adopts an extensive-quantitative strategy. The key technique for collecting data was the indirect questionnaire.

The inclusive criteria underlying the empirical selection included: i) patients who attended or were admitted to this psychiatric emergency service, and ii) patients who understood and agreed to participate in the study, encompassing all diseases. On the other hand, the following patients were not included: patients who (i) were very drowsy, ii) were unable to speak, or (iii) had a cognitive impairment that prevented them from understanding and participating in the study.

The difficulties inherent to different clinical situations, associated with the acute phases of psychiatric disorders and cognitive impairment, were a methodological challenge for the selection and recruitment of participants in this study. Therefore, the convenience sampling method was used.

Taking into account the objectives of this study, a database was created with the following di- mensions: (i) Sociodemographic characteristics; (ii) Assessment of cognitive status; (iii) Assessment of the degree of therapeutic adherence; and iv) Assessment of the degree of insight. The analysis of the sociodemographic characteristics sought to locate the individual within the system of social relations and highlight the different indicators related to gender, age, level of education, and professional situation. Patients' cognitive status was assessed through the revised Portuguese version of the Mini-Mental State Examination (MMSE; Morgado, Rocha, Maruta, Guerreiro, \& Martins, 2009); the degree of therapeutic adherence was assessed using the Measure of Adherence to Treatment (MAT), which reflects a version of the Morisky scale, validated by Delgado and Lima (2001) for the Portuguese reality; and the degree of insight was measured through the Marková and Berrios Insight Scale, which was validated in Portugal by Vanelli et al. (2010).

Patients participated on a voluntary basis and were informed, in detail, about the study objectives and topics under analysis. Confidentiality and anonymity were ensured and any doubts were clarified. Patients who agreed to participate were asked to fill in and sign an informed consent form. In the process of building the questionnaire, a draft version was pre-tested using a sample of 11 patients from the psychiatric emergency service. Afterward, the final version of the questionnaire was applied during a 5-month period, between October 2015 and March 2016.

The psychiatric emergency service is open 24/7. Data were collected during the $8 \mathrm{am}-4 \mathrm{pm}$ shift from Monday to Friday. During the data collection period, a total of 522 patients attended the psychiatric emergency service, and 96 of these patients were able to be contacted. After applying the selection criteria, the sample was composed of 49 participants. The questionnaire consisted of a structured interview, during which the researcher completed the questions. Data collection was a time-consuming task because patients were expected to fully understand the research objectives. In addition, these methodological and ethical procedures involved issues related to social relations, which implied a preparatory phase for the development of relationships of trust with the patients, always respecting the participants' response rhythms and refusals. Data were also collected through other informa- 
tion sources such electronic clinical records from nurses and psychiatrists. During the task of planning and implementing the research, all nursing-related ethical and deontological principles were observed. The project was presented and approved by the ethics committee of the hospital institution included in this study. Data were statistically analyzed using the Statistical Package for the Social Sciences (SPSS), version 21.

\section{Results}

The characterization of this sample, consisting of 49 patients, reveals a relatively balanced gender distribution: $46.9 \%$ of men and $53.1 \%$ of women. Participants were aged between 18 and 79 years $(M=45.8$ years; $S D=14.8)$. They had different levels of education, which was strongly associated with the age groups $(\mathrm{M}=7.8$ years; $S D=3.6$ ), with the youngest participants having significantly higher educational levels than the older participants. The analysis of the close social relationships, family relationships, and cohabitation revealed that $24.5 \%$ of peo- ple lived alone and $75.5 \%$ lived in significantly different family contexts. With regard to marital status, $34.7 \%$ were divorced, $34.7 \%$ were single, $20.4 \%$ were married/cohabiting, and $10.2 \%$ were widowers. It should be noted that there is a high inactivity rate $(61.2 \%)$, which resulted from situations of unemployment/ joblessness (34.7\%) and retirement (26.5\%), while a low percentage of patients reported being employed $(38.8 \%)$. The most common medical diagnoses were depressive disorders $(26.5 \%)$ and schizophrenia (24.5\%).

A total of 35 nursing diagnoses was identified in this sample of 49 patients. Table 1 shows the 17 most common diagnoses that were selected. The most common nursing diagnosis was impaired adherence to the therapeutic regimen (69.4\%). The aggregated data shows that there is a high prevalence of diagnoses related to the psychological domain of mood and anxiety, such as sadness $(63.3 \%)$, anxiety $(61.2 \%)$, and low self-esteem (55.1\%). A high prevalence of consumption of psychoactive substances such as tobacco $(63.3 \%)$, alcohol $(46.9 \%)$, and drugs $(24.5 \%)$ was also found.

Table 1

Frequency of nursing diagnoses

\begin{tabular}{lcc}
\hline Nursing Diagnoses & $n$ & $\%$ \\
\hline Alcohol abuse & 23 & 46.9 \\
Drug abuse & 12 & 24.5 \\
Tobacco abuse & 31 & 63.3 \\
Impaired acceptance of health status & 24 & 49 \\
Impaired adherence to the therapeutic & 34 & 69.4 \\
regimen & & \\
Agitation & 20 & 40.8 \\
Hallucination & 8 & 16.3 \\
Anxiety & 30 & 61.2 \\
Low self-esteem & 27 & 55.1 \\
Impaired cognition & 13 & 26.5 \\
Delusional activity & 22 & 44.9 \\
Disorientation & 25 & 51 \\
Depressed mood & 23 & 46.9 \\
Suicidal ideation & 13 & 26.5 \\
Social isolation & 14 & 28.6 \\
Altered perception & 17 & 34.7 \\
Sadness & 31 & 63.3 \\
\hline
\end{tabular}


Analysis of the nursing diagnoses based on the sociodemographic characteristics

Table 2 shows the distribution of frequencies in the social dimensions. The analysis of the nursing diagnoses when compared to the gender dimension was based on chi-square tests $\left(X^{2}\right)$ and their significance levels $(p)$. This analysis showed that diagnoses regarding behavioral changes, such as agitation (56.5\%), and consumption of psychoactive substances, such as alcohol abuse (69.6\%), drug abuse (43.5\%), and tobacco abuse (78.3\%), were more common in men. No statistically significant differences were found between men and women in the remaining diagnoses.

With regard to age, Pearson's correlation coefficient showed a significant correlation in six diagnoses, which reflects a generational effect. This generation pattern revealed a higher prevalence of psychoactive substance abuse, such as alcohol abuse $(r=-.33 ; p=.022)$, drug abuse $(r=-.31 ; p=.031)$, and tobacco abuse $(r=-.40 ; p=.032)$ among younger people. In turn, the prevalence of low self-esteem $(r$ $=.45, p=.021)$, sadness $(r=.28, p=.050)$, and impaired cognition $(r=.31, p=.030)$ increases with age. With regard to education, significant correlations were found between the lower level of education and low self-esteem and impaired cognition. Although the remaining results revealed no statistically significant differences, a pattern was found in which lower levels of education correspond to an impaired acceptance of the health status and a lower degree of adherence. An association was also found between lower levels of education and more depressive disorders, with a higher prevalence of sadness, depressed mood, and suicidal ideation.

Cohabitation revealed a very strong pattern showing a persistently higher prevalence of problems in the various bio-psycho-social dimensions among people who live alone. In addition to this pattern, statistically significant associations were also found between living alone and social isolation $(p<.001)$, anxiety $(p=.01)$, and low self-esteem $(p=.05)$. In turn, and despite the heterogeneity of situations, the integration in family relationships seems to be a protective factor against mental health problems.

Table 2

Association between nursing diagnoses and sociodemographic dimensions

\begin{tabular}{|c|c|c|c|c|c|c|c|c|c|c|c|c|}
\hline \multirow{3}{*}{ Nursing Diagnoses } & \multicolumn{3}{|c|}{ Gender } & \multirow{2}{*}{\multicolumn{3}{|c|}{$\begin{array}{c}\text { Age } \\
\text { (years) }\end{array}$}} & \multirow{2}{*}{\multicolumn{3}{|c|}{$\begin{array}{c}\text { Education } \\
\text { (years) }\end{array}$}} & \multicolumn{3}{|c|}{ Living arrangements } \\
\hline & \multirow{2}{*}{$\begin{array}{l}\mathrm{M} \\
\%\end{array}$} & \multicolumn{2}{|l|}{ F } & & & & & & & \multirow{2}{*}{$\begin{array}{c}\text { Family } \\
\%\end{array}$} & \multirow{2}{*}{$\begin{array}{c}\text { Alone } \\
\%\end{array}$} & \multirow[b]{2}{*}{$p$} \\
\hline & & $\%$ & $p$ & Mean & $r$ & $p$ & Mean & $r$ & $p$ & & & \\
\hline Alcohol abuse & 69.6 & 26.9 & $.03^{*}$ & 41 & -.33 & $.02^{*}$ & 6.1 & -.17 & .23 & 36.3 & 68.2 & $.05^{*}$ \\
\hline Drug abuse & 43.5 & 7.7 & $.01^{*}$ & 38 & -.31 & $.03^{*}$ & 8.8 & .16 & .29 & 27.8 & 38.8 & .28 \\
\hline Tobacco abuse & 78.3 & 50.0 & $.05^{*}$ & 41 & -.40 & $.03^{*}$ & 8.6 & .09 & .52 & 59.0 & 78.2 & .22 \\
\hline $\begin{array}{l}\text { Impaired acceptance } \\
\text { of health status }\end{array}$ & 52.2 & 46.2 & .67 & 47 & .08 & .59 & 6.8 & -.13 & .37 & 43.6 & 55.5 & .41 \\
\hline $\begin{array}{l}\text { Impaired adherence } \\
\text { to the therapeutic } \\
\text { regimen }\end{array}$ & 73.9 & 65.4 & .30 & 46 & .03 & .84 & 6.9 & -.26 & .73 & 66.7 & 80.0 & .23 \\
\hline Agitation & 56.5 & 26.9 & $.03^{*}$ & 43 & -.17 & .24 & 9.1 & .21 & .13 & 41.0 & 40.0 & .95 \\
\hline Hallucination & 21.7 & 11.5 & .34 & 44 & -.06 & .70 & 8.5 & .08 & .59 & 15.4 & 20.0 & .73 \\
\hline Anxiety & 65.2 & 46.2 & .18 & 43 & -.22 & .13 & 7.5 & -.12 & .43 & 38.1 & 60.0 & $.01^{*}$ \\
\hline
\end{tabular}




\begin{tabular}{lcccccccccccccc}
\hline Low self-esteem & 47.8 & 61.5 & .34 & 52 & .45 & $.02^{*}$ & 6.6 & -.29 & $.05^{*}$ & 51.3 & 70.0 & $.05^{*}$ \\
Impaired cognition & 30.4 & 23.1 & .56 & 53 & .31 & $.03^{*}$ & 5.2 & -.30 & $.04^{*}$ & 25.6 & 30.0 & .78 \\
Delusional activity & 56.5 & 34.6 & .12 & 44 & -.14 & .34 & 7.5 & -.10 & 0.49 & 41.0 & 49.5 & .28 \\
Disorientation & 47.8 & 53.8 & .67 & 44 & -.10 & .51 & 7.7 & -.39 & .79 & 46.2 & 72.1 & .18 \\
Depressed mood & 39.1 & 53.8 & .52 & 49 & .21 & .15 & 6.5 & -.26 & .35 & 51.3 & 52.8 & .41 \\
Suicidal ideation & 21.7 & 30.8 & .47 & 49 & .13 & .38 & 7.1 & -.13 & .37 & 23.1 & 40.0 & .28 \\
Social isolation & 39.1 & 19.2 & .12 & 51 & .21 & .16 & 6.8 & -.09 & .55 & 10.3 & 100.0 & $.00^{*}$ \\
Altered perception & 47.8 & 23.1 & .07 & 47 & .07 & .63 & 8.1 & .04 & .78 & 30.8 & 50.0 & .25 \\
Sadness & 60.9 & 65.4 & .77 & 49 & .28 & $.05^{*}$ & 6.8 & -.22 & .12 & 43.7 & 68.3 & .33 \\
\hline
\end{tabular}

${ }^{*}$ Statistically significant correlations.

The analysis of the comparison between the most common nursing diagnoses and medical diagnoses (schizophrenia and depressive disorders) showed significant differences (Table 3). Firstly, the cases of schizophrenia seemed to lead to a higher prevalence of nursing problems and diagnosis than the cases of depressive disorders. In addition, the cases of schizophrenia showed a higher prevalence of diagnoses related to the psychological domain and behavior changes: delusional activity (75\%), altered perception (66.7\%), hallucination (41.7\%), disorientation (75\%), and agitation (58.3\%). Furthermore, cases of schizophrenia revealed a high frequency of the diagnosis of impaired adherence to the therapeutic regimen $(83.3 \%)$, in contrast with the lowest percentage found in depressive disorders (46.2\%). Another difference was found in the domain of social rela- tions, in which the most common diagnosis among the cases of schizophrenia was social isolation $(66.7 \%)$. With regard to the consumption of psychoactive substances, the major difference was found in drug abuse (41.7\%), mostly cannabinoids, associated with schizophrenia. Similar patterns were found in tobacco and alcohol consumption, associated with schizophrenia and depressive disorders. However, it should be noted that, among the several psychiatric disorders, a high prevalence of alcohol abuse (46.2\%) was found in depressive disorders. Depressive disorders included diagnoses related to mood and anxiety, such as sadness (100\%), depressed mood (100\%), low self-esteem $(100 \%)$, and anxiety (76.9\%). Suicidal ideation had lower scores $(38.5 \%)$ and frequencies very similar to the cases of schizophrenia (33.3\%). 
Table 3

Distribution of the frequencies of nursing diagnoses according to medical diagnoses

\begin{tabular}{|c|c|c|c|c|c|c|c|c|}
\hline \multirow{3}{*}{ Nursing Diagnoses } & \multicolumn{8}{|c|}{ Medical diagnoses } \\
\hline & \multicolumn{2}{|c|}{ Schizophrenia } & \multicolumn{2}{|c|}{ Depression } & \multicolumn{2}{|c|}{ Other psychoses } & \multicolumn{2}{|c|}{ Other diseases } \\
\hline & $N$ & $\%$ & $N$ & $\%$ & $N$ & $\%$ & $N$ & $\%$ \\
\hline Alcohol abuse & 7 & 58.3 & 6 & 46.2 & 5 & 38.5 & 5 & 45.5 \\
\hline Drug abuse & 5 & 41.7 & 2 & 15.4 & 3 & 23.1 & 2 & 18.2 \\
\hline Tobacco abuse & 8 & 66.7 & 7 & 53.8 & 9 & 69.2 & 7 & 63.6 \\
\hline $\begin{array}{l}\text { Impaired acceptance of } \\
\text { health status }\end{array}$ & 7 & 58.3 & 4 & 30.8 & 8 & 61.5 & 5 & 45.5 \\
\hline $\begin{array}{l}\text { Impaired adherence to } \\
\text { the therapeutic regimen }\end{array}$ & 10 & 83.3 & 6 & 46.2 & 10 & 76.9 & 8 & 72.7 \\
\hline Agitation & 7 & 58.3 & 0 & 0 & 7 & 53.8 & 6 & 54.5 \\
\hline Hallucination & 5 & 41.7 & 0 & 0 & 2 & 15.4 & 1 & 9.1 \\
\hline Anxiety & 6 & 50 & 10 & 76.9 & 7 & 53.8 & 4 & 36.4 \\
\hline Low self-esteem & 7 & 58.3 & 13 & 100 & 4 & 30.8 & 3 & 27.3 \\
\hline Impaired cognition & 3 & 25 & 1 & 7.7 & 3 & 23.1 & 6 & 54.5 \\
\hline Delusional activity & 9 & 75 & 3 & 23.1 & 7 & 53.8 & 3 & 27.3 \\
\hline Disorientation & 9 & 75 & 2 & 15.4 & 5 & 38.5 & 9 & 81.8 \\
\hline Depressed mood & 4 & 33.3 & 5 & 38.5 & 1 & 7.7 & 3 & 27.3 \\
\hline Suicidal ideation & 4 & 33.3 & 13 & 100 & 1 & 7.7 & 5 & 45.5 \\
\hline Social isolation & 8 & 66.7 & 2 & 15.4 & 3 & 23.1 & 1 & 9.1 \\
\hline Altered perception & 8 & 66.7 & 3 & 23.1 & 5 & 38.5 & 1 & 9.1 \\
\hline Sadness & 7 & 58.3 & 13 & 100 & 6 & 46.2 & 5 & 45.5 \\
\hline
\end{tabular}

Association between the nursing diagnoses and the cognitive function, insight, and therapeutic adherence

According to Carvalho (2010), the formulation of nursing diagnoses is a rigorous process which uses an adequate set of assessment tools that are available to nurses and must be integrated into their daily work. In this article, three instruments were used to assess the most important intervention domains, as reported by the nursing teams from the psychiatric emergency service: cognitive status, degree of adherence to the therapeutic regimen, and degree of insight. The subsequent analysis focused on the nursing diagnoses based on the results of these three mental health assessment instruments. In each of these instruments, the ranges were identified: the MMSE ranges between 0 and 20, the MAT ranges between 1 and 6, and the Mar- ková and Berrios Insight Scale ranges between 0 and 30 .

The assessment of the cognitive domain, based on the MMSE scores, reflects a consistency between low MMSE scores and the nursing diagnosis of impaired cognition. On the other hand, lower MMSE scores are associated with key nursing-related dimensions that pose challenges to nurses' performance in emergency settings, particularly problems related to the low degree of adherence to the therapeutic regimen, disorientation, delusional activity, and impaired acceptance of health status. The lower mean scores found in the domain of therapeutic adherence, which was measured using the MAT, reflected poor adherence in cases associated with impaired acceptance of health status, delusional activity, consumption of illicit psychoactive substances, altered perception, and, to a lesser 
degree, with social isolation. In turn, the degree of adherence to the therapeutic regimen was higher in cases associated with the diagnosis of depressed mood and sadness. The domain of insight was measured using Marková and Berrios Insight Scale. The low scores of insight found in this study are closely associated with the diagnosis of impaired acceptance of health status. Overall, the lower degree of insight is associated with the diagnoses of impaired adherence to the therapeutic regimen, impaired $\operatorname{cog}$ nition, delusional activity, and disorientation. On the contrary, the highest scores of insight are associated with the diagnosis of sadness.

Table 4

Distribution of the frequencies of nursing diagnoses according to cognitive dimensions (MMSE), therapeutic adherence (MAT), and insight (Marková and Berrios Insight Scale).

\begin{tabular}{|c|c|c|c|c|c|c|c|c|c|}
\hline \multirow{2}{*}{ Nursing Diagnoses } & \multicolumn{3}{|c|}{ MMSE (0-20) } & \multicolumn{3}{|c|}{ MAT (1-6) } & \multicolumn{3}{|c|}{ Insight (0-30) } \\
\hline & Mean & $r$ Pearson & $p$ & Mean & $r$ Pearson & $p$ & Mean & $r$ Pearson & $p$ \\
\hline Alcohol abuse & 26 & 0.14 & 0.33 & 4.2 & 0.13 & 0.43 & 13 & 0.12 & 0.41 \\
\hline Drug abuse & 24 & -0.02 & 0.89 & 4.2 & $-0.33^{*}$ & 0.04 & 13 & 0.02 & 0.91 \\
\hline Tobacco abuse & 25 & 0.16 & 0.27 & 3.9 & -0.2 & 0.22 & 13 & 0.13 & 0.38 \\
\hline $\begin{array}{l}\text { Impaired acceptance } \\
\text { of health status }\end{array}$ & 22 & $-0.41^{*}$ & 0 & 3.5 & $-0.41^{*}$ & 0.01 & 9 & $-0.59^{*}$ & 0 \\
\hline $\begin{array}{l}\text { Impaired adherence } \\
\text { to the therapeutic } \\
\text { regimen }\end{array}$ & 23 & $-0.41^{*}$ & 0 & 3.8 & $-0.39^{*}$ & 0.01 & 11 & $-0.48^{*}$ & 0 \\
\hline Agitation & 26 & 0.21 & 0.15 & 4 & -0.06 & 0.72 & 14 & 0.22 & 0.13 \\
\hline Hallucination & 22 & -0.2 & 0.17 & 3.4 & -0.25 & 0.12 & 11 & -0.13 & 0.36 \\
\hline Anxiety & 24 & 0.01 & 0.96 & 4.2 & 0.07 & 0.68 & 13 & 0.14 & 0.35 \\
\hline Low self-esteem & 24 & -0.04 & 0.78 & 4.3 & 0.19 & 0.24 & 13 & 0.05 & 0.73 \\
\hline Impaired cognition & 22 & $-0.29^{*}$ & 0.04 & 4.2 & 0.02 & 0.88 & 10 & -0.23 & 0.12 \\
\hline Delusional activity & 22 & $-0.29^{*}$ & 0.04 & 3.6 & $-0.35^{*}$ & 0.03 & 10 & $-0.31^{*}$ & 0.03 \\
\hline Disorientation & 22 & $-0.38^{*}$ & 0.01 & 4.2 & 0.09 & 0.59 & 11 & -0.28 & 0.05 \\
\hline Depressed mood & 25 & 0.02 & 0.88 & 4.5 & $0.33^{*}$ & 0.04 & 13 & 0.11 & 0.47 \\
\hline Suicidal ideation & 25 & 0 & 0.98 & 4.3 & 0.11 & 0.52 & 13 & 0.08 & 0.58 \\
\hline Social isolation & 22 & -0.22 & 0.14 & 3.5 & -0.29 & 0.07 & 11 & -0.2 & 0.16 \\
\hline Altered perception & 24 & -0.05 & 0.74 & 3.8 & -0.15 & 0.37 & 13 & 0.1 & 0.49 \\
\hline Sadness & 26 & 0.25 & 0.09 & 4.4 & $0.40^{*}$ & 0.01 & 14 & $0.44^{*}$ & 0 \\
\hline
\end{tabular}

\section{Discussion}

Due to the specificities and limitations of conducting this type of research in a psychiatric emergency service, the sample was limited to 49 participants which, in turn, limited further statistical analyses. However, some aspects should be highlighted. The analysis of the social dimension shows that the convergence of categories that reflect the weak- ening of social ties - people living alone, who are unemployment or divorced - is associated with a higher prevalence of nursing diagnoses such as low adherence to the therapeutic regimen, higher alcohol consumption, impaired acceptance of health status or delusional activity. The diagnosis of social isolation reflects situations of social inequality, which affects people with lower financial resources and in situations of greater poverty. Based on the additional analysis resulting from interviews 
with patients and content analysis, it can be concluded that the problems related to social inequalities are associated with financial difficulties, as for example the difficulty in buying medication or using health care services; however, these problems seem to be mainly related to social uprooting, very low levels of education, and, finally, loneliness. This analysis is in line with the results of studies on the impact of social inequalities on health inequalities (Antunes, 2014).

It should be noted that the diagnosis of impaired adherence to the therapeutic regimen was more prevalent in this multidimensional analysis. In fact, it is a nursing diagnosis found in both genders, in different age groups, in different social inclusion contexts, and associated with different psychiatric disorders. It should be noted that depressive disorders seem to be the only exception, being associated with a higher degree of adherence to the therapeutic regimen. In the emergency service, cases of delusional activity are more associated with schizophrenia and less associated with depressed mood. However, a more detailed analysis of the results shows that the cases of depressed mood with delusional activity are associated with low adherence to the therapeutic regimen. Therefore, the difference in the degree of adherence is not explained by the type of disease alone, but rather by the presence of delusional activity which negatively affects the adherence to the therapeutic regimen by reducing the degree of insight. These findings reveal a trend which was already found in other studies (Beck, Cavelti, Kvrgic, Kleim, \& Vauth, 2011) in which the presence of more severe psychotic episodes, combined with changes in perception and thought, have a negative influence on therapeutic adherence.

The analysis of these results showed some nursing-related specificities in a psychiatric emergency service. Clinical cases of delusional activity seem to be the most challenging ones for nursing practice in the psychiatric emergency service. In fact, delusional activity adversely affects several other dimensions such as adherence to the therapeutic regimen, acceptance of health status, cognitive function, and behavioral changes, namely agitation.

This study was conducted in a psychiatric emergency service and showed that the use of nursing diagnoses enables a more detailed analysis of the actual intervention contexts, which are still very influenced by medical diagnoses. A more detailed study of these inter- vention contexts, to which the formulation of nursing diagnoses is associated, would allow for the identification of nursing priorities and problems and, in turn, leads to autonomy gains in nursing practice.

The combination between the practical nursing care delivery - and theoretical - reflection and analysis - domains demonstrates that, as Carvalho (2010) states, that the formulation of nursing diagnoses, and their prevalence within a specific setting, can challenging. However, this task should certainly be more successful than formulating and implementing diagnoses in practical situations, at the service of those who use a psychiatric emergency service. In the formulation of diagnoses, and according to Passos et al. (2014) when discussing nursing foci of attention, this study also had difficulties in identifying the presence or absence of some nursing foci of attention and formulating diagnoses because some ICNP concepts have overlapping characteristics. This fact hindered the use of the collected data in the formulation of nursing foci of attention and diagnoses.

\section{Conclusion}

The specificities of nursing care delivery in a psychiatric emergency service reveal patterns in the signs and symptoms that are nurses' main focus of attention. Therefore, it is important to highlight some patterns of nursing problems and needs that are the basis for the formulation of diagnoses in psychiatric emergency settings. On the one hand, a pattern was found in which the psychological domain of mood, characterized by depressed mood, sadness, low self-esteem, and anxiety, is associated with higher degrees of adherence, better acceptance of the disease, and lower level of cognitive impairment. On the other hand, another prevalent pattern was found in which psychotic symptoms, accompanied by delusional activity, hallucination, behavior changes, and lack of insight, shows a greater association with low therapeutic adherence and psychoactive substance abuse. Cases of schizophrenia are more challenging and require greater attention from nurses.

This study highlighted the need to use a common and standardized terminology based on the formulation of nursing diagnoses with a view to systematizing health care. This research line should be further explored in quantitative studies, but qualitative research strategies should also be used with nurses who 
work in psychiatric emergency settings to help them formulate nursing diagnoses and overcome the difficulties encountered in this process.

\section{References}

Amaral, A. (2010). Prescriçôes de enfermagem em saúde mental. Loures, Portugal: Lusociência.

Antunes, R. (2014). Desigualdades sociais, desigualdades de saúde. In M. Leandro \& B. Monteiro (Eds.), Saude no prisma da sociologia: Olhares plurais (pp. 117-130). Viseu, Portugal: Psicosoma.

Antunes, R. (2016). Promoção da adesão terapêutica na pessoa com doença mental (Master's dissertation). Retrieved from http://hdl.handle. net/10400.26/17188

Beck, E., Cavelti, M., Kvrgic, S., Kleim, B., \& Vauth, R. (2011). Are we addressing the 'right stuff' to enhance adherence in schizophrenia?: Understanding the role of insight and attitudes towards medication. Schizophrenia Research, 132(1), 42-49. doi: 10.1016/j.schres.2011.07.019

Buriola, A. A., Kantorski, L. P., Sales, C. A., \& Matsuda, L. M. (2016). Atuaçáo do enfermeiro no serviço de emergência psiquiátrica: Avaliação pelo Método de Quarta Geração. Texto \& Contexto - Enfermagem, 25(1), 1-9. doi: 10.1590/0104070720160004540014

Carvalho, J. (2010). Da avaliação ao diagnóstico. In C. Sequeira \& L. Sá (Eds.), Do diagnóstico à interven- ção em saúde mental (pp. 65-67). Lisboa, Portugal: Sociedade Portuguesa de Enfermagem de Saúde Mental.

Conselho Internacional de Enfermeiros. (2016). CIPE Versão 2015: Classificação Internacional para a Prática de Enfermagem. Lisboa, Portugal: Ordem dos Enfermeiros.

Delgado, A., \& Lima, M. (2001). Contributo para a validação concorrente de uma medida de adesão aos tratamentos. Psicologia, Saúde e Doenças, 2(2), 81100. Retrieved from http://www.scielo.mec.pt/pdf/ $\mathrm{psd} / \mathrm{v} 2 \mathrm{n} 2 / \mathrm{v} 2 \mathrm{n} 2 \mathrm{a} 06 . \mathrm{pdf}$

Morgado, J., Rocha, S., Maruta, C., Guerreiro, M., \& Martins, P. (2009). Novos valores normativos do Mini-Mental State Examination. Sinapse, 9(2), 10 16.

Observatório Português dos Sistemas de Saúde. (2015). Acesso aos cuidados de saúde, um direito em risco?: Relatório de Primavera 2015. Retrieved from http:// www.opss.pt/sites/opss.pt/files/RelatorioPrimavera2015.pdf

Passos, J., Sequeira, C., \& Fernandes, L. (2014). Focos de enfermagem em pessoas mais velhas com problemas de saúde mental. Revista de Enfermagem Referência, 4(2), 81-91. doi: 10.12707/RIV14002

Sequeira, C. (2006). Introdução à prática clínica, Coimbra, Portugal: Quarteto.

Vanelli, I., Chendo, I., Levy, P., Figueira, M., Góis, C., Santos, J., \& Markova, I. (2010). Adaptação para português da Escala de Insight Marková e Berrios. Acta Médica Portuguesa, 23(6), 1011-1016. Retrieved from http://www.actamedicaportuguesa.com/ revista/index.php/amp/article/view/748/425 